ScIDoC

\section{Common Patient Positioning Errors in Digital Panoramic Radiographs of Patients Visiting A Private Dental Institution}

Research Article

Rushabh Kamdar ${ }^{1}$, Vivek Narayan ${ }^{2 *}$, Arun $\mathrm{M}^{3}$

${ }^{1}$ Saveetha Dental College and Hospitals, Saveetha Institute of Medical and Technical Sciences(SIMATS), Saveetha University, Chennai 600077 , Tamil $\mathrm{Nadu}$, India.

${ }^{2}$ Senior Lecturer, Department of Oral Medicine and Radiology. Saveetha Dental College and Hospitals, Saveetha Institute of Medical and Technical Sciences(SIMATS), Saveetha University, Chennai 600 077, Tamil Nadu, India.

${ }^{3}$ Senior Lecturer, Department of Oral and Maxillofacial Surgery, Saveetha Dental College and Hospitals, Saveetha Institute of Medical and Technical Sciences(SIMATS), Saveetha University, Chennai 600 077, Tamil Nadu, India.

\title{
Abstract
}

A panoramic radiograph provides an overview of both dental arches and closely related anatomical structures. Panoramic radiographs are prone for patient positioning errors resulting in faulty images. The aim of the study is to evaluate the prevalence of the most common patient positioning errors that occurs during the acquisition of a panoramic radiograph. The study was done in a university setting and is a retrospective study. The total sample size of the study was 1000 digital Ortho Pantomo Gram (OPGs). The OPG were selected randomly using convenient sampling. All the necessary information was collected and entered in Microsoft excel spreadsheet and subsequently transferred to SPSS version 23.0 for statistical analysis. Chi square tests were employed to find the association between different variables and $\mathrm{p}<5 \%$ was considered statistically significant. On examining the 1000 panoramic radiographs for positioning errors, $68.2 \%$ had no errors and the total amount of positioning errors were $31.8 \%$. Among the various positioning errors, horizontal errors were the maximum and was at $7.3 \%$ followed by patient movement error which was $6.4 \%$ and tongue positioning error at $6.2 \%$. In addition to the prevalence of common positioning errors, association between age and positioning errors were found to be statistically significant $(p<0.05)$. The age group $<20$ years were found to be having the maximum positioning errors. Association between gender and positioning errors were found to be statistically not significant $(p>$ 0.05). Effective measures must be implemented to reduce these errors.

Keywords: Panoramic Radiographs; OPG; Errors; Patient Positioning.

\section{Introduction}

Panoramic radiographs or Ortho Pantomo Gram (OPG) are the most commonly used radiographs for imaging dental structures among dentists due to their various advantages. It provides an overview of both the dental arches and a view of a large number of related anatomical structures such as maxillary sinuses, the temporomandibular joint and the hyoid bone. The procedure of image acquisition is simple and is also meant for patients whose mouth opening is limited. As the panoramic radiograph provides an overall picture of the mandible and the maxillofacial region there is a slight compromise in the level of detail of the dental and related anatomic structures when compared with an intraoral radiograph [1].

The patient is positioned with their spine straight and by holding the handles present in the machine. The patient brings their feet slightly forward and keeps their neck upright, this is referred to as the 'ski' position by some authors. The patient bite on the bite peg by bringing their upper and lower incisors edge to edge. The head is restrained using temple supports in the machine and using the light beam as a positioning guide for orienting the mid sagittal plane and the Frankfort plane. The patient is advised to keep their tongue against the palate [2]. This proper positioning of the patient is paramount since this ensures the patient's jaws and maxillofacial region are placed in the focal trough region. The struc-

\section{*Corresponding Author}

Vivek Narayan,

Senior Lecturer, Department of Oral Medicine and Radiology, Saveetha Dental College and Hospitals, Saveetha Institute of Medical and Technical Sciences(SIMATS),

Saveetha University, Chennai 600 077, Tamil Nadu, India.

Tel: +91- 9962866419

E-mail: viveknarayan@saveetha.com

Received: September 03, 2019

Accepted: September 29, 2019

Published: September 30, 2019

Citation: Rushabh Kamdar, Vivek Narayan, Arun M. Common Patient Positioning Errors in Digital Panoramic Radiographs of Patients Visiting A Private Dental Institution. Int J Dentistry Oral Sci. 2019;S2:02:008:28-32. doi: http://dx.doi.org/10.19070/2377-8075-SI02-02008

Copyright: Vivek Narayan 2019. This is an open-access article distributed under the terms of the Creative Commons Attribution License, which permits unrestricted use, distribution and reproduction in any medium, provided the original author and source are credited. 
tures lying inside the focal trough are clearly imaged and those structures lying in front or in the back of the focal trough are blurred out. This is the importance of proper patient positioning.

The panoramic image is prone for errors that occur during patient positioning. It may contain reflections of various structures and shadows of soft tissues and anatomical air spaces. The dental professional must have knowledge about these common positioning errors in order to efficiently interpret the radiograph. Objects like spectacles, neck chains, earrings and dentures must be removed before exposure. The tongue positioning if not proper can lead to radiolucent artifacts above the maxillary teeth. The errors that happen during a panoramic exposure hinder the radiographic details of the pathology which leads to diagnostic errors. The quality of any radiograph depends on proper positioning of the patient and accurate technique in order to have an image of an acceptable diagnostic quality [3].

Previously our team has conducted numerous studies which include in vitro studies [4], review [5], case report, survey [6], microscopic studies [7] and clinical trial [8-18]. Now we are focussing on epidemiological studies, Hence the aim of the present study was to determine the prevalence of common patient positioning errors in digital panoramic radiographs in patients visiting a private dental college. While searching the literature it was found that studies associating gender with patient positioning errors were not done and only one study has been performed to find the association of age with radiographic errors, hence, the present study also attempted to find the association of gender and age with patient positioning errors.

\section{Materials and Methods}

\section{Study design}

This is a retrospective study conducted in a private dental institution. The panoramic radiographs were reviewed for different types of patient positioning errors by a trained examiner. The advantage of conducting the study in an institutional set up provides easy access to patient records. From the archives of dental radiology of the institution, the OPGs of 1000 patients were examined. A wide age range is selected for the study. The institutional ethical committee provided approval for the study (SDC/SIHEC/2020/ DIASDATA/0619-0320).

\section{Inclusion criteria}

1. OPGs with patient positioning errors

2. Patients from $<20$ years to 50 years of age

\section{Exclusion criteria}

1. Incomplete patient data

2. Duplicate patient data

3. OPG with other types of errors

The following patient positioning errors were assessed,

1. Spinal ghosting shadows - occurs due to flexion of the neck

2. Excessive forward positioning - the incisors appear narrowed

3. Excessive backward positioning - the image looks magnified, widened and anterior teeth are out of focus

4. Tongue positioning error - causes a radiolucent band across the film

5. Horizontal error - occurs due to patient turning their head during an exposure

6. Chin tipped up (grumpy face error) - occurs due to distorted occlusal plane

7. Chin tipped down (smiley face error) - occurs due to out of focus upper incisors and distorted occlusal plane

8. Patient movement errors - occurs when the patient is not instructed to stay still during the exposure

\section{Sampling}

A total of 1000 OPGs of patients were examined to find out the prevalence of patient positioning errors. Convenient sampling method was used to select the OPGs for the study and they were chosen randomly. The data obtained from the radiographs were cross verified with the case records of the patients.

\section{Data collection}

All the data after thorough checking for duplicates, incomplete entries and cross verification with case records were entered in Microsoft excel spreadsheet in order to organise the data. The variables obtained from the data included age, gender, presence and absence of radiographic error and the type of patient positioning error. Here the age, gender are the independent variables and the types of patient positioning error is the dependent variable.

\section{Statistics}

The statistical analysis of the obtained data was performed by the SPSS software version 23.0. The data from the excel spreadsheet was transferred to SPSS software for analysis. Chi square tests were employed in order to find the association between different variables. The $\mathrm{p}$ value less than $5 \%$ was considered statistically significant. The final results are presented in the form of graphs and tables for further interpretation and discussion.

\section{Results and Discussion}

Out of 1000 OPGs examined for the various patient positioning errors $31.8 \%$ had patient positioning errors and $68.2 \%$ had no errors. Among the various positioning errors, horizontal errors were the highest and was at $7.3 \%$ followed by patient movement error which was $6.4 \%$ and tongue positioning error at $6.2 \%$. Study by Schiff T et al., [19] revealed that out of the 1000 OPGs $20.3 \%$ were error free, the positioning errors were $98.1 \%$, head turned error was $6.9 \%$, tongue not raised was $25.7 \%$ and patient movement error was 3\%. All these observations were in contrast to the present study. This might be due to the differences in the sample characteristics. Study done by Kaviani F et al., [20] found that patient positioning errors were the most common and were at $78 \%$ and among that head rotation errors were found to be the maximum (39.5\%) and the least was patient movement during exposure (2.4\%). Choi BR et al., [21] also found that patient positioning errors to be 139 in number and it is the maximum in their study. The study by Dhillon M et al., [22] found that failure to position tongue against palate to be the maximum and was at 
$55.7 \%$ followed by slumped position at $35 \%$ and patient positioned backward at $30 \%$.

The distribution of the positioning error among the males and females were studied. Males had 16\% and females had 15.8\% positioning errors [figure 1]. The association between the gender and presence and absence of positioning errors was found to be statistically not significant (Chi-square value $=0.486 ; \mathrm{p}=0.486 ; \mathrm{p}>$ $0.05)$. The difference between the genders for positioning errors was negligible. This observation was in accordance to the study done by Belgin CA et al., [23] who also found that there was no significant correlation between gender and panoramic radiograph errors $(p>0.05)$.

The distribution of the various types of positioning errors among the males and females were studied. 'No error' in the OPG were seen the highest in both genders. This was followed by horizontal errors, where males had $3.7 \%$ and females had $3.6 \%$ of horizontal errors the differences between the genders were negligible [figure 2]. This was followed by patient movement errors which was prevalent in males and was at 3.3\%.The association between gender and types of positioning errors were found to be statistically not significant (Chi-square value $=1.432 ; \mathrm{p}=0.994 ; \mathrm{p}>0.05$ ). This is again in support of the study done by Belgin CA et al (23) where no significant correlation was found between gender and radiographic errors.

The distribution of the positioning errors among the different age groups were studied. Positioning errors were present highest in the age group of less than 20 years and was $22.3 \%$ followed by $21-30$ years at $8 \%, 41-50$ years at $0.9 \%$ and $31-40$ years at $0.6 \%$ [figure 3]. The association between age and positioning errors was found to be statistically significant (Chi-square value= 48.127; $\mathrm{p}=0.000 ; \mathrm{p}<0.05$ ). In our literature search the only study done by Belgin CA et al (23) found the association between age and radiographic errors and it was found that the association between the variables was statistically significant $(p<0.05)$. It was stated that the rate of the radiographic errors increased significantly with increasing patient age. The errors were mostly seen in the age group $>56$ years. The association between the variables is in accordance with the present study but the observations are in contrast with the present study since the errors were mostly seen in the younger age groups. This difference may be due to the sample size and ethnicity of the population.

The distribution of the various types of positioning errors among the different age groups were studied. Horizontal error had the highest occurrence and is more prevalent in the age group < 20 years and was at $71.2 \%$. This was followed by patient movement error which was also prevalent in the $<20$ years age group and was at $65.6 \%$. The age group 21 - 30 was affected next with horizontal error at $26 \%$ and patient movement error at $31.3 \%$ [table 1]. The association between age and type of positioning errors were found to be statistically significant (Chi-square value $=$ 95.496; $p=0.000 ; p<0.05)$. Belgin et al., [23] found that the association between type of error and age were statistically significant $(\mathrm{p}<0.05)$ and slumped position and patient movement errors were common in $>56$ years and patient positioned forward error was more common in 19 - 24 years and 36 - 45 years. The association between the variables is in accordance with the present study but the observations are in contrast to the present study since it was the horizontal error and patient movement which was commonly occurring in the age groups $<20$ years and $21-30$ years. Again sample size and other characteristics of the sample might have led to this difference.

The present study has some limitations, the sample sizes were relatively small and all images have been evaluated by a single examiner. Studies with a larger sample, having more than one examiner to evaluate the radiographs, assessment of parameters such as diagnostic quality and errors due to patient preparation and technical errors can be included in the future.

\section{Conclusion}

The present study reveals that a considerably high amount of positioning errors was present in the sample. Among the various positioning errors, horizontal errors were the highest followed by patient movement errors and tongue positioning errors. No significant association was seen between gender and positioning

Figure 1. Bar graph depicts the association between the gender and the presence (blue) and absence (orange) of positioning error. $\mathrm{X}$ axis represents the gender and $\mathrm{Y}$ axis represents the total number of OPG (Ortho Pantomo Gram). Chi square analysis reveals that the association between the variables is not statistically significant (Chi-square value $=0.486 ; p=0.486 ; p$ $>$ 0.05). A slight male predilection was seen for the presence of positioning errors but the difference was negligible compared to females.

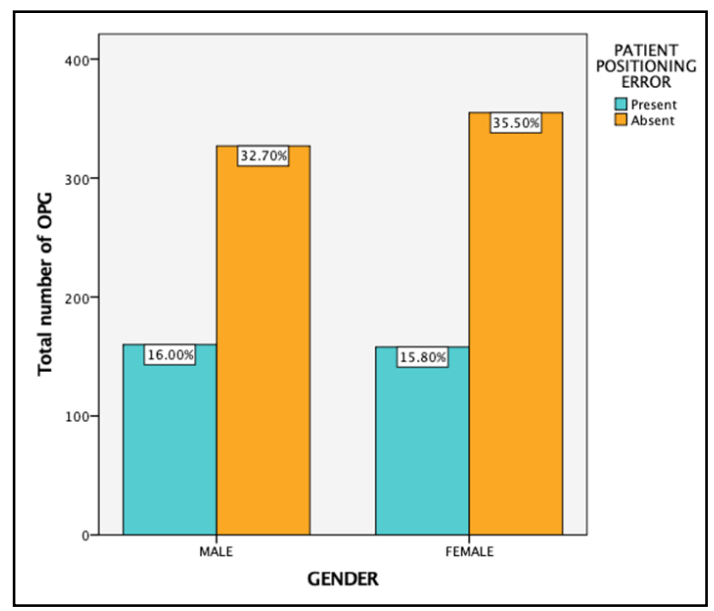


Figure 2. Bar graph depicts the association between the gender (male - blue, female - purple) and types of positioning errors. $\mathrm{X}$ axis represents the total number of $O P G$ and the $Y$ axis represents the types of positioning error for males and females with different types of positioning errors. Chi square analysis reveals that the association between the variables is statistically not significant (Chi-square value $=1.432 ; \mathrm{p}=0.994 ; \mathrm{p}>0.05)$. 'No error' in OPG were seen highest in males and females. This was followed by horizontal errors being the most common error and almost equally distributed in males and females.

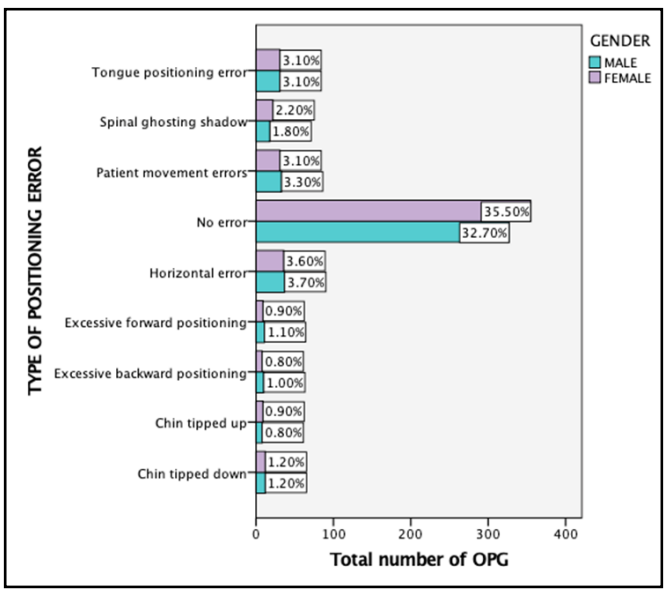

Figure 3. Bar graph depicts the association between age groups and presence (blue) and absence (orange) of positioning error. The $\mathrm{X}$ axis represents the age groups and $\mathrm{Y}$ axis represents the total number of OPG with the presence or absence of positioning error. Chi square analysis reveals that the association between the variables is statistically significant (Chisquare value $=48.127 ; p=0.000 ; p<0.05)$. Positioning errors were present highest in the age group of less than 20 years followed by 21 - 30 years, 41 - 50 years and 31 - 40 years.

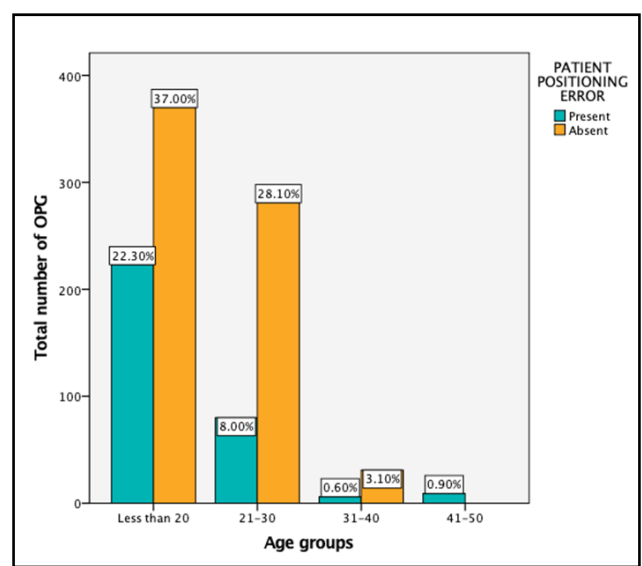

Table 1. Depicts the association between age groups and type of positioning error. Chi square analysis reveals that the association between the variables is statistically significant (Chi-square value= 95.496; $\mathrm{p}=0.000 ; \mathrm{p}<0.05$ ). Horizontal error has the highest occurrence and is more prevalent in the age group $<20$ years. This was followed by patient movement error which was also prevalent in the $<20$ years age group.

\begin{tabular}{|c|c|c|c|c|c|c|c|c|c|c|}
\hline & & & & Types o & f positionin & $g$ errors & & & & \\
\hline $\begin{array}{c}\text { Age } \\
\text { groups (in } \\
\text { years) }\end{array}$ & No error & $\begin{array}{l}\text { Chin } \\
\text { tipped } \\
\text { down }\end{array}$ & $\begin{array}{l}\text { Chin } \\
\text { tipped up }\end{array}$ & $\begin{array}{c}\text { Excessive } \\
\text { backward } \\
\text { position- } \\
\text { ing }\end{array}$ & $\begin{array}{l}\text { Excessive } \\
\text { forward } \\
\text { position- } \\
\text { ing }\end{array}$ & $\begin{array}{l}\text { Horizon- } \\
\text { tal error }\end{array}$ & $\begin{array}{l}\text { Patient } \\
\text { move- } \\
\text { ment } \\
\text { errors }\end{array}$ & $\begin{array}{l}\text { Spinal } \\
\text { ghosting } \\
\text { shadow }\end{array}$ & $\begin{array}{l}\text { Tongue } \\
\text { position- } \\
\text { ing error }\end{array}$ & Total \\
\hline$<20$ & $\begin{array}{c}370 \\
(54.3 \%) \\
\end{array}$ & $\begin{array}{c}20 \\
(83.3 \%) \\
\end{array}$ & $\begin{array}{c}10 \\
(58.8 \%) \\
\end{array}$ & $\begin{array}{c}12 \\
(66.7 \%) \\
\end{array}$ & $16(80 \%)$ & $\begin{array}{c}52 \\
(71.2 \%) \\
\end{array}$ & $\begin{array}{c}42 \\
(65.6 \%) \\
\end{array}$ & $\begin{array}{c}24 \\
(60.0 \%) \\
\end{array}$ & $\begin{array}{c}47 \\
(75.8 \%) \\
\end{array}$ & $\begin{array}{c}593 \\
(59.3 \%) \\
\end{array}$ \\
\hline $21-30$ & $\begin{array}{c}281 \\
(41.2 \%) \\
\end{array}$ & $4(16.7 \%)$ & $4(23.5 \%)$ & $5(27.8 \%)$ & $3(15 \%)$ & $\begin{array}{c}19 \\
(26.0 \%) \\
\end{array}$ & $\begin{array}{c}20 \\
(31.3 \%) \\
\end{array}$ & $\begin{array}{c}15 \\
(37.5 \%) \\
\end{array}$ & $\begin{array}{c}10 \\
(16.1 \%) \\
\end{array}$ & $\begin{array}{c}361 \\
(36.1 \%) \\
\end{array}$ \\
\hline $31-40$ & $31(4.5 \%)$ & $0(0 \%)$ & $2(11.8 \%)$ & $1(5.6 \%)$ & $0(0 \%)$ & $2(2.7 \%)$ & $1(1.6 \%)$ & $0(0 \%)$ & $0(0 \%)$ & $37(3.7 \%)$ \\
\hline $41-50$ & $0(0 \%)$ & $0(0 \%)$ & $1(5.9 \%)$ & $0(0 \%)$ & $1(5 \%)$ & $0(0 \%)$ & $1(1.6 \%)$ & $1(2.5 \%)$ & $5(8.1 \%)$ & $9(0.9 \%)$ \\
\hline Total & $\begin{array}{c}682 \\
(100 \%)\end{array}$ & $24(100 \%)$ & $17(100 \%)$ & $18(100 \%)$ & $20(100 \%)$ & $73(100 \%)$ & $64(100 \%)$ & $40(100 \%)$ & $62(100 \%)$ & $\begin{array}{c}1000 \\
(100 \%)\end{array}$ \\
\hline
\end{tabular}


errors whereas a significant association was present between age and various positioning errors. These errors can make the radiograph diagnostically unacceptable. Hence measures must be taken to avoid these errors happening during a panoramic exposure especially in the younger age group of patients as the present study showed errors to be present more in $<20$ and 21 - 30 age groups.

\section{Acknowledgement}

The authors are thankful to the dental institute for providing a platform to perform the research study.

\section{References}

[1]. Pettit GG. Panoramic radiography. Dent Clin North Am. 1971 Jan;15(1):169-82.

[2]. Langlais RP, Langland OE, Nortjé CJ. Diagnostic imaging of the jaws. Williams \& Wilkins; 1995:661

[3]. Horton PS, Sippy FH, Kerber PE, Paule CL. Analysis of interpretations of full-mouth and panoramic surveys. Oral Surg Oral Med Oral Pathol. 1977 Sep;44(3):468-75.Pubmed PMID: 269343.

[4]. Venugopal A, Uma Maheswari TN. Expression of matrix metalloproteinase-9 in oral potentially malignant disorders: A systematic review. J Oral MaxillofacPathol. 2016 Sep-Dec;20(3):474-479.Pubmed PMID: 27721614.

[5]. Chaitanya NC, Muthukrishnan A, Babu DBG, Kumari CS, Lakshmi MA, Palat G, et al. Role of Vitamin E and Vitamin A in Oral Mucositis Induced by Cancer Chemo/Radiotherapy- A Meta-analysis. J ClinDiagn Res. 2017 May;11(5):ZE06-ZE09.Pubmed PMID: 28658926.

[6]. Subashri A, Maheshwari TN. Knowledge and attitude of oral hygiene practice among dental students. Res J Pharm Technol. 2016;9(11):1840-2.

[7]. Maheswari TNU, Venugopal A, Sureshbabu NM, Ramani P. Salivary micro RNA as a potential biomarker in oral potentially malignant disorders: A systematic review. Ciji Yi XueZaZhi. 2018 Apr-Jun;30(2):55-60.Pubmed PMID: 29875583

[8]. Misra SR, Shankar YU, Rastogi V, Maragathavalli G. Metastatic hepatocellular carcinoma in the maxilla and mandible, an extremely rare presentation. ContempClin Dent. 2015 Mar;6(Suppl 1):S117-21.Pubmed PMID: 25821363.

[9]. Steele JC, Clark HJ, Hong CHL, Jurge S, Muthukrishnan A, Kerr AR, et al. World Workshop on Oral Medicine VI: an international validation study of clinical competencies for advanced training in oral medicine. Oral Surg
Oral Med Oral Pathol Oral Radiol. 2015 Aug;120(2):143-51.e7.Pubmed PMID: 25861956

[10]. Muthukrishnan A, Warnakulasuriya S. Oral health consequences of smokeless tobacco use. Indian J Med Res. 2018 Jul;148(1):35-40.

[11]. Patil SR, Maragathavalli G, Araki K, Al-Zoubi IA, Sghaireen MG, Gudipaneni RK, et al. Three-rooted mandibular first molars in a Saudi Arabian population: a CBCT study. Pesqui. Bras. Odontopediatria Clin. 2018 Aug 27;18(1):4133.

[12]. Chaitanya NC, Muthukrishnan A, Krishnaprasad CMS, Sanjuprasanna G, Pillay P, Mounika B. An Insight and Update on the Analgesic Properties of Vitamin C. J Pharm Bioallied Sci. 2018 Jul-Sep;10(3):119-125.Pubmed PMID: 30237682

[13]. Rohini S, Kumar VJ. Incidence of dental caries and pericoronitis associated with impacted mandibular third molar-A radiographic study. Res J Pharm Technol. 2017;10(4):1081-4.

[14]. Dharman S, Muthukrishnan A. Oral mucous membrane pemphigoid - Two case reports with varied clinical presentation. J Indian SocPeriodontol. 2016 Nov-Dec;20(6):630-634.Pubmed PMID: 29238145.

[15]. Muthukrishnan A, Bijai Kumar L, Ramalingam G. Medication-related osteonecrosis of the jaw: a dentist's nightmare. BMJ Case Rep. 2016 Apr 6;2016:bcr2016214626.Pubmed PMID: 27053542.

[16]. Subha M, Arvind M. Role of magnetic resonance imaging in evaluation of trigeminal neuralgia with its anatomical correlation. Biomed. Pharmacol. J. 2019 Mar 25;12(1):289-96.

[17]. Muthukrishnan A, Bijai Kumar L. Actinic cheilosis: early intervention prevents malignant transformation. BMJ Case Rep. 2017 Mar 20;2017:bcr2016218654.Pubmed PMID: 28320702.

[18]. Choudhury P, Panigrahi RG, Maragathavalli, Panigrahi A, Patra PC. Vanishing roots: first case report of idiopathic multiple cervico-apical external root resorption. J ClinDiagn Res. 2015 Mar;9(3):ZD17-9.Pubmed PMID: 25954713.

[19]. SchiffT, D'Ambrosio J, Glass BJ, Langlais RP, McDavid WD. Common positioning and technical errors in panoramic radiography. J Am Dent Assoc. 1986 Sep;113(3):422-6.Pubmed PMID: 3463616

[20]. Kaviani F, Johari M, Esmaeili F. Evaluation of common errors of panoramic radiographs in tabriz faculty of dentistry. J Dent Res Dent Clin Dent Prospects. 2008 Dec;2(3):99-101.Pubmed PMID: 23277854.

[21]. Choi BR, Choi DH, Huh KH, Yi WJ, Heo MS, Choi SC, et al.Clinical image quality evaluation for panoramic radiography in Korean dental clinics. Imaging Sci Dent. 2012 Sep;42(3):183-90.Pubmed PMID: 23071969.

[22]. Dhillon M, Raju SM, Verma S, Tomar D, Mohan RS, Lakhanpal M, et al Positioning errors and quality assessment in panoramic radiography. Imaging Sci Dent. 2012 Dec;42(4):207-12.Pubmed PMID: 23301205.

[23]. Belgin CA, Serindere G. Evaluation of error types and quality on panoramic radiography. Int. J. Dent. Res. 2019 Dec 31;9(3):99-104 